\title{
Amizade na Adultez: Fatores Individuais, Ambientais, Situacionais e Diádicos ${ }^{1}$
}

\author{
Luciana Karine de Souza \\ Universidade Federal de Minas Gerais \\ Claudio Simon Hutz. \\ Universidade Federal do Rio Grande do Sul
}

\begin{abstract}
RESUMO
$\mathrm{O}$ presente estudo investigou fatores individuais, ambientais, situacionais e diádicos no relacionamento de melhor amizade, segundo o modelo desenvolvimental de Fehr. Participaram 676 adultos com idades entre 18 e 58 anos. Foram utilizados questionários formulados para abordar itens referentes aos fatores contemplados do modelo de Fehr. Observou-se a importância da proximidade residencial como fator ambiental na formação das amizades em geral, e da similaridade na constituição da amizade, especialmente entre homens e seus amigos. Entre mulheres, o contato semanal por telefone destacou-se das outras modalidades. A incidência considerável de melhores amizades extras tanto em homens como em mulheres suscita questionamentos tanto sobre a percepção do participante sobre o que consiste uma melhor amizade, ou sobre o uso do construto melhor amizade como representativo de um relacionamento exclusivo e de elevado status entre dois indivíduos.
\end{abstract}

Palavras-chave: amizade; relacionamento; adultez.

\begin{abstract}
Friendship Among Adults: Individual, Environmental, Situational, and Dyadic Factors

The present study investigated individual, environmental, situational, and dyadic factors in bestfriends relationships according to Fehr's model. The participants, 676 adults 18 to 58 years-old, completed questionnaires to assess factors related to Fehr's model. The results showed the importance of living proximity as an environmental factor in the establishment of friendships in general and of similarity in the constitution of friendship, mainly between males and their friends. Among women, the frequency of contact by phone was a major factor. The high frequency of additional best-friends for both men and women raised questions about their understanding of what is a best-friend and about the use of this construct to describe an exclusive and high status relationship between two individuals.
\end{abstract}

Keywords: friendship; relationships; adulthood.

No conjunto de estudos sobre felicidade e satisfação de vida, é conhecida a ampla pesquisa conduzida por Argyle (2001) com amostras de vários países. O autor identificou aspectos relevantes para a felicidade das pessoas nas distintas culturas que investigou, destacando três grandes fatores: trabalho, lazer e relacionamentos. Com respeito aos relacionamentos, apontou três tipos mais associados à felicidade para os indivíduos: família, romance e amizade. O presente trabalho investiga características dos relacionamentos de amizade em adultos, dado que são interações significativas que proporcionam satisfação de vida às pessoas.

Os relacionamentos de amizade vêm sendo estudados há aproximadamente um século, mas os trabalhos empíricos têm se mostrado mais freqüentes nos últi- mos 30 anos. Desta gama de trabalhos destaca-se o montante de investigações sobre amizade em crianças e adolescentes (Bukowski, Newcomb \& Hartup, 1996), volume este igualmente significativo na produção de estudos brasileiros sobre o tema (Antoniazzi e cols., 2001; Daudt, 1997; Lisboa \& Koller, 2003; Piotto \& Rubiano, 1999; Rohde, Ferreira, Zomer, Forster \& Zimmermann, 1998; Tortella, 2007). Contudo, a amizade em adultos ainda é pouco investigada no Brasil (Erbolato, 2001; Kipper, 2003; Rezende, 2000), conseqüência de um generalizado interesse nas etapas anteriores à adultez, com reflexo na produção científica em Psicologia (Souza, Gauer \& Hutz, 2004).

$\mathrm{Na}$ adultez a amizade caracteriza-se por uma homogeneidade em aspectos como sexo, idade, estado 
civil, escolaridade, status ocupacional, renda, religião, etnia, traços de personalidade, interesses e atividades compartilhados, número de amigos, duração e tipos de amizade, trocas afetivas, ajuda instrumental, aconselhamento, confiança, freqüência de interação, aceitação, respeito e contato físico (não-sexual) (Bell, 1981; Blieszner \& Adams, 1992; Fehr, 1996; Parks \& Floyd, 1996). Nas diferenças de sexo, enquanto os homens valorizam mais atividades conjuntas, as amizades entre mulheres destacam-se pela troca de experiências emocionais (Wright, 1985), referida também como auto-revelação (isto é, abertura para falar sobre os próprios pensamentos e sentimentos) (Parks \& Floyd, 1996).

As teorias disponíveis no estudo dos relacionamentos direcionam-se a cobrir relacionamentos familiares e românticos (Berscheid \& Regan, 2005). Para os relacionamentos de amizade não há teorias específicas. Contudo, analisando uma ampla gama de estudos empíricos sobre o tema, Fehr (1996) propôs um modelo desenvolvimental para fundamentar os relacionamentos de amizade. Segundo a autora, as amizades se formam, se desenvolvem, se mantêm e terminam mediante a inter-relação de quatro conjuntos de fatores: ambientais, situacionais, individuais e diádicos.

\section{Modelo desenvolvimental para relacionamentos de amizade}

Os fatores ambientais que interferem na formação, desenvolvimento, manutenção e declínio das amizades são a proximidade residencial, o local onde se passa o dia, a densidade populacional e aspectos comunicacionais da rede social. Nos estudos conduzidos sobre proximidade residencial, condomínios fechados e alojamentos universitários são locais férteis para a formação de amizades, apontando que: vizinhos de porta ou de andar são mais preferidos que outros vizinhos; diferenças etárias e raciais são ultrapassadas na formação de amizades em função da proximidade entre residências; e melhores amigos tendem a morar perto um do outro. Fehr (1996) também identificou que várias pesquisas apontam que muitas amizades adultas originam-se do ambiente onde as pessoas passam a maior parte do dia, como o local de trabalho, a universidade ou o bairro residencial, visto que entram em contato freqüentemente. Nos estudos sobre amizade que abordaram a densidade populacional, grandes centros urbanos e cidades pequenas (ou zonas rurais) contrastam quanto à rapidez na formação das amizades. A título de exemplo, um estudo comparou um grupo de universitários que partiram de uma cidade pequena para estudar em uma cidade densamente povoada, com um grupo de alunos que percorreu o caminho inverso para ingressar na universidade. Passados dois meses da entrada na universidade, o segundo grupo relatou o dobro da média de amigos novos na comparação com o primeiro; seis meses depois, ambos relataram aproximadamente o mesmo número de amigos. Outra pesquisa apontou que, apesar de as pessoas levarem mais tempo para fazerem amigos em grandes centros urbanos, esses ambientes propiciam mais ocasiões para interações informais, na comparação com cidades pequenas, oferecendo, assim, mais oportunidades favoráveis à formação de amizades. Com respeito à comunicação na rede social, amigos atuais são fonte de novos amigos, ou seja, pode-se formar novas amizades através deles, intencionalmente ou não. Além disso, a reação de pessoas de uma mesma rede de relacionamentos (cônjuge, familiares etc.) exerce influência sobre a formação, o desenvolvimento e a manutenção de uma dada amizade (Fehr). Sobre este último fator, os pais podem, por exemplo, estimular ou desestimular o filho a fazer amizade com uma determinada criança.

No conjunto dos fatores situacionais, encontram-se a probabilidade de interação, a freqüência de contato, a dependência e a disponibilidade. Com relação à probabilidade de interação, os estudos demonstram que, quando se antecipa a interação com uma pessoa conhecida, há uma tendência a aumentar aspectos positivos e diminuir os negativos com a finalidade de fazer com que os encontros futuros sejam os mais agradáveis possíveis. Quanto à freqüência de contato, Fehr (1996) observou, na literatura empírica, que quanto mais as pessoas vêem um determinado indivíduo (inclusive mediante fotografias), mais elas gostam dele, sem a necessidade de interação. Também se constatou que quanto mais se familiariza com alguém, mais se admite semelhanças com esse indivíduo. Sobre a dependência, Fehr encontrou que, em situações nas quais outra pessoa está no lugar de nos fornecer recompensa ou punição, isto é, quando dependemos de alguém, há uma tendência a se gostar mais dessa pessoa. Outro pré-requisito para o surgimento de uma amizade é o fato de que, para se tornarem amigas, duas pessoas devem estar disponíveis. Esta condição é avaliada através da mútua checagem de acessibilidade (a probabilidade de oportunidades futuras para interação freqüente em atividades típicas de amigos) e de comprometimentos preexistentes (se a pessoa já tem muitos amigos, se está envolvida em trabalho ou estudos que consomem muito tempo, ou se está engajada em 
um relacionamento amoroso exclusivo). Há estudos que apontam correlações positivas entre número de amigos e de amigos próximos e freqüência e qualidade de contatos presenciais, por telefone e mediante visitas e festas (Veenhoven, 1994).

Por intermédio dos fatores individuais compreende-se por que nem todas as pessoas são percebidas como elegíveis à categoria de amigas. Critérios de exclusão e de inclusão são utilizados na pré-seleção de candidatos a amigos. Em um primeiro momento, as pessoas selecionam aqueles de quem não é possível ser amigo, e posteriormente avaliam amigos em potencial (Rodin, 1982, citado por Fehr, 1996). Há dois critérios de exclusão: o critério de desagrado (dificilmente se gosta de uma pessoa que possui uma qualidade condenável, por mais que possua qualidades apreciadas) e o de discrepância quanto a aspectos como raça, escolaridade, aparência física, idade e vestuário. Este último critério é empregado como estratégia para evitar investimento de energia e atenção com pessoas das quais provavelmente não se gostará como amigas.

São cinco os critérios de inclusão de indivíduos no escopo de possíveis candidatos à formação de uma amizade: aparência física, habilidade social, responsividade, timidez, e similaridade (Fehr, 1996). Estudos têm indicado que as pessoas gostam de interagir com pessoas bonitas ou fisicamente atraentes, e que estas recebem mais respostas positivas nas interações, capacitando-as a desenvolver mais autoconfiança e habilidades sociais. A propósito, fazer amigos requer habilidades sociais como responder apropriadamente ao que a pessoa diz, mostrar uma seqüência apropriada de olhares ou de postura durante uma conversa, e seguir regras apropriadas para intercalar a vez de falar. Uma melhoria nestas habilidades faz com que as pessoas gostem mais do indivíduo. Quanto à responsividade, na avaliação de Fehr sobre as pesquisas que trataram do tema, faz-se mais amigos quando a pessoa se interessa pelos outros do que quando se dedica a fazer os outros se interessarem por ela. Para o critério timidez, os trabalhos têm demonstrado que pessoas tímidas apresentam menos iniciativa para iniciar uma conversa, são mais lentas para responder aos comentários dos outros durante conversas, sorriem menos e estabelecem menos contato visual. Em outras palavras, tímidos são menos responsivos. Esses comportamentos levam o parceiro de conversa a pensar que a pessoa não quer interagir. Entretanto, observa-se que as amizades de tímidos são mais duradouras. Finalmente, o fator similaridade é considerado o ponto de partida para a amizade, bem como o processo pelo qual a amizade se torna mais próxima (Fehr), como referido anteriormente com relação à homogeneidade das amizades adultas.

Quanto aos fatores diádicos - quarto e último conjunto de fatores do modelo de Fehr (1996) - dois se destacam: o apreço mútuo e a auto-revelação. $\mathrm{O}$ primeiro faz parte do julgamento inicial que um indivíduo forma sobre o outro. De acordo com Fehr, "provavelmente vamos atrair outra pessoa se acreditamos que ela goste de nós. Se esse apreço inicial conduzir ou não a uma amizade dependerá, em grande medida, de o que você e a outra pessoa revelarão um ao outro" (p. 61). Nessa direção, o apreço mútuo é pré-requisito à auto-revelação, isto é, da abertura para falar de assuntos particulares com o amigo. Fehr ressalta que nos estágios iniciais de um relacionamento é importante que as revelações sejam recíprocas, porque elas facilitam o desenvolvimento da confiança.

Conforme o modelo desenvolvimental de Fehr (1996) para os relacionamentos de amizade, a formação, o desenvolvimento, a manutenção e o declínio da amizade dependerão da convergência de fatores ambientais, situacionais, individuais e diádicos. Nesse sentido, tem-se observado, por exemplo, que densidade populacional, local onde se passa o dia, freqüência de contato, expectativa de interação futura, boas habilidades sociais, semelhanças variadas, apreço mútuo e auto-revelação influenciam no surgimento, no desenrolar e na continuidade da amizade entre duas pessoas.

$\mathrm{Na}$ extensa revisão da literatura sobre amizade que realizou, Fehr (1996) relata que, de um lado, a amizade vem sendo definida como um relacionamento entre pessoas que não são familiares, parentes ou parceiras sexuais; de outro, contudo, identificou trabalhos nos quais os participantes apontaram cônjuges ou familiares como amigos. Bell (1981), por exemplo, afirma que um dos aspectos fundamentais da definição de amizade é a ausência de laços familiares ou de parentesco entre amigos. Segundo o autor, mesmo que haja amizade entre familiares, ser amigo e ser familiar são dois papéis sociais mutuamente exclusivos em um mesmo indivíduo. Essa incompatibilidade é justificada quando situações de comparação ou de competição entre familiares e amigos desafiam o relacionamento entre estes últimos. Além disso, não é possível escolher os próprios familiares e parentes. Em contraste, as pessoas se envolvem em relacionamentos de amizade voluntariamente, ou seja, por livre opção. Conseqüentemente, a amizade é um relacionamento pessoal e privado, ao qual não são impostos valores ou normas culturais. Essa visão difere com a de culturas nas quais o envolvimento pessoal é secundário às deman- 
das institucionais da sociedade (Bell). No entanto, Blieszner e Adams (1992) argumentam que, se a amizade fosse um relacionamento imune a influências sociais e culturais, as pesquisas não apontariam a influência de muitos destes fatores na formação, desenvolvimento e manutenção das amizades. Em virtude de haver poucos estudos sobre amizade em adultos no Brasil, no presente trabalho optou-se por permitir que os participantes referissem a amizades com familiares e parentes.

O objetivo do presente estudo foi de explorar algumas das variáveis presentes no modelo de Fehr (1996), descrevendo-se características da amizade em adultos. Dos fatores ambientais, investigou-se a proximidade residencial entre o participante e suas amizades, mas com atenção à proximidade geográfica (mesma cidade). Dos fatores situacionais, examinouse o contato semanal. Finalmente, uma aproximação aos fatores diádicos foi empreendida ao se perguntar ao participante se a pessoa que ele indicou como melhor amiga sabe de seu status de melhor amizade. Outros aspectos da amizade foram estudados, como incidência de amizades próximas e sexo dessas amizades; a indicação da melhor amizade e aspectos associados, como origem, duração, tipo de relacionamento atual com o melhor amigo (p. ex., ex-colega, familiar etc.); e incidência e sexo de outras melhores amizades. Em complemento, visto que a literatura relata diferenças de sexo nas amizades de homens e de mulheres, busca-se investigar tais diferenças para as características estudadas.

\section{MÉTODO}

\section{Participantes}

Participaram do presente estudo 676 adultos na faixa etária de 18 a 58 anos, regularmente matriculados em distintos cursos de graduação de uma universidade pública situada em Porto Alegre, $\mathrm{RS}^{2}$. Constaram na amostra 423 mulheres $(63 \%)$, com idade média de 23 anos (DP $=6,3)$, e 253 homens $(37 \%)$, com 23,6 anos de idade em média (DP $=7,1$ ). Do total de participantes, $88 \%$ são solteiros e $81 \%$ residiam em Porto Alegre.

\section{Instrumentos}

O primeiro instrumento foi um questionário sóciodemográfico introdutório desenvolvido especialmente para o estudo. Foram solicitadas ao participante informações como sexo, idade, curso universitário, estado civil, naturalidade, cidade de residência, religião e atividade remunerada.
O segundo instrumento consta de questões sobre amizades próximas e sobre uma melhor amizade, pedindo ao participante informações sobre os seguintes itens: 1) Número de amigos próximos (definidas para o participante como amizades que se destacam das demais, limitadas a dez indicações); 2) Número de amizades próximas masculinas; 3 ) Número de amizades próximas femininas; 4) Número de amizades que moram atualmente na mesma cidade que o participante; 5) Número de amizades próximas que encontra freqüentemente; 6) Indicação de uma melhor amizade e sexo.

O terceiro e último instrumento apresenta questões específicas sobre a melhor amizade, composto dos itens: 1) Tempo de amizade com a melhor amizade (em anos e meses); 2) Local onde se conheceram: faculdade, colégio, trabalho, praia, festa, Internet, ou outro lugar; 3) Relação atual que possui com a melhor amizade: colega de faculdade, colega de trabalho, namoro/noivado/casamento, familiar/parente, ou outra; 4) Se residem na mesma cidade (sim ou não); 5) Se a pessoa indicada sabe que é a melhor amiga do participante: sabe, não sabe, ou não sei se sabe; 6) Freqüência semanal de contato face a face com a melhor amizade; 7) Freqüência semanal de contato por telefone; 8) Freqüência semanal de contato por e-mail; 9) Freqüência de outras melhores amizades e sexo destas amizades (limitadas a cinco indicações).

\section{Procedimentos e análise dos dados}

A aplicação dos questionários foi coletiva e em sala de aula, com aproximadamente 40 minutos de duração. Todos os participantes assinaram um Termo de Consentimento Livre e Esclarecido, que assegurava anonimato, disponibilidade para esclarecer dúvidas e liberdade para desistir de participar do estudo, dentre outros aspectos. Os questionários do presente estudo constam de uma pesquisa conduzida para a adaptação e validação dos Questionários McGill de Amizade (Souza \& Hutz, 2007). São descritos e analisados os dados do questionário introdutório sobre amizades próximas e escolha da melhor amizade, que antecedeu os Questionários McGill, e os dados do questionário com questões complementares sobre a melhor amizade, que sucedeu os Questionários McGill.

Foram calculadas freqüências, porcentagens e médias para as variáveis investigadas. Comparações de médias mediante teste $t$ (incidência de amizades próximas, de mesmo sexo, de sexo oposto, que residem na mesma cidade e que encontra freqüentemente; contato semanal com a melhor amizade; e incidência de melhores amizades extras, de mesmo sexo e de 
sexo oposto) e busca de associações entre categorias por meio do teste de qui-quadrado e análise de resíduos ajustados estandardizados (Everitt, 1977) (sexo da melhor amizade, origem do relacionamento, tipo de relacionamento atual, se o participante e o amigo residem na mesma cidade, e se ele sabe do status de melhor amizade que o participante lhe atribui) foram conduzidas com a finalidade de averiguar significância estatística nas diferenças e associações, por sexo do participante. $\mathrm{O}$ nível de significância adotado foi de 0,05 em todos os testes.

\section{RESULTADOS}

Primeiramente são apresentados os dados referentes às amizades próximas, por sexo do participante. A Tabela 1 apresenta médias e desvios-padrão para incidência de amigos homens, de amigas mulheres, total de amizades, incidência de amizades que moram na mesma cidade e de amizades que encontra freqüentemente.

TABELA 1

Sexo das Amizades Próximas, das que Residem na Mesma Cidade e que Encontra Freqüentemente, por Sexo do Participante

\begin{tabular}{lllllll}
\hline & \multicolumn{2}{c}{ Média } & \multicolumn{3}{c}{$\mathrm{DP}$} & \multicolumn{3}{c}{$\mathrm{n}$} \\
\cline { 2 - 7 } Amizades próximas & $\mathrm{F}$ & $\mathrm{M}$ & $\mathrm{F}$ & $\mathrm{M}$ & $\mathrm{F}$ \\
\hline Total & 6,6 & 6,6 & 2,5 & 2,7 & 423 & 253 \\
Amigas mulheres & 4,6 & 2,2 & 2,1 & 1,6 & 423 & 253 \\
Amigos homens & 2,0 & 4,6 & 1,5 & 2,2 & 423 & 253 \\
\hline Residentes na mesma cidade & 4,7 & 4,9 & 2,6 & 2,9 & 420 & 250 \\
\hline Encontra freqüentemente & 4,5 & 4,9 & 2,4 & 2,9 & 420 & 253 \\
\hline
\end{tabular}

Nota. $F=$ feminino; $M=$ masculino.

Foram efetuadas comparações de médias mediante teste $t$ entre sexo do participante e as variáveis referentes a amizades próximas. Diferenças significativas foram encontradas para amizades próximas de mesmo sexo, ou seja, tanto os participantes homens como as mulheres possuem mais amizades próximas de mesmo sexo: $t(674)=18,43, \mathrm{p}<0,001$; e $t(674)=15,35$, $\mathrm{p}<0,001$, respectivamente. As demais diferenças entre participantes do sexo masculino e do sexo feminino para total de amizades próximas, número de amizades que residem na mesma cidade e de amizades que encontra freqüentemente - não foram significativas.
A Tabela 2 mostra os resultados para sexo da melhor amizade e origem do relacionamento. $\mathrm{O}$ teste de qui-quadrado apontou associação significativa entre sexo do participante e as variáveis sexo da melhor amizade e origem da amizade. A associação entre sexo do participante e da melhor amizade indicou o predomínio de amizades de mesmo sexo: $\chi^{2}(1, \mathrm{~N}=676)=$ $191,4, \mathrm{p}<0,001$. Quanto ao local onde o participante e sua melhor amizade se conheceram, os homens apontaram significativamente mais a praia do que as mulheres, como local de origem da amizade: $\chi^{2}(8, N=676)=19,59, \mathrm{p}<0,01$.

TABELA 2

Sexo da Melhor Amizade e Local de Origem do Relacionamento, por Sexo do Participante

\begin{tabular}{lrr}
\hline & $\begin{array}{c}\text { Feminino } \\
\mathrm{n}=423 \\
\mathrm{f}(\%)\end{array}$ & $\begin{array}{c}\text { Masculino } \\
\mathrm{n}=253 \\
\mathrm{f}(\%)\end{array}$ \\
\hline Melhor amizade & $345(82)$ & $71(28)$ \\
Sexo & $78(18)$ & $182(72)$ \\
Feminino & & \\
Masculino & $154(36)$ & $84(33)$ \\
\hline Local de origem & $69(16)$ & $36(14)$ \\
Colégio & $44(10)$ & $34(13)$ \\
Faculdade & $45(11)$ & $30(12)$ \\
Família & $26(6)$ & $17(7)$ \\
Vizinhança & $1(0,2)$ & $9(4)$ \\
Trabalho & $5(1)$ & $7(3)$ \\
Praia & $13(3)$ & $3(1)$ \\
Internet & $66(16,8)$ & $33(13)$ \\
Festa & & $13(1)$ \\
Outros & & \\
\hline
\end{tabular}


A Tabela 3 apresenta o tipo de relacionamento atual com a melhor amizade, se o participante e o amigo residem na mesma cidade, e se ele sabe do status de melhor amizade que o participante lhe atribui. O teste de qui-quadrado não detectou associação significativa entre sexo do participante e relação atual com a melhor amizade, nem para o compartilhamento da cidade de residência, mas o detectou para o conhecimento que o melhor amigo tem de seu status, com os participantes homens destacando-se na categoria "não sabe", isto é, mais homens referiram que seu melhor amigo não sabe do elevado status que possui na rede de amizades do participante do sexo masculino, na comparação com as mulheres e as demais alternativas de resposta: $\chi^{2}(2, \mathrm{~N}=676)=6,03, \mathrm{p}<0,05$.

\section{TABELA 3}

Relacionamento Atual com o Melhor Amigo, Residência na Mesma Cidade e Conhecimento do Status pelo Amigo, por Sexo do Participante

\begin{tabular}{lrr}
\hline & $\begin{array}{c}\text { Feminino } \\
\mathrm{n}=423\end{array}$ & $\begin{array}{c}\text { Masculino } \\
\mathrm{n}=253 \\
\mathrm{f}(\%)\end{array}$ \\
Melhor amizade & $\mathrm{f}(\%)$ & $60(24)$ \\
Relacionamento atual & & $36(14)$ \\
Ex-colega de colégio & $102(24)$ & $58(23)$ \\
Colega de faculdade & $62(15)$ & $25(10)$ \\
Apenas amizade & $106(25)$ & $23(9)$ \\
Familiar/parente & $46(11)$ & $22(9)$ \\
Parceiro romântico & $40(9,5)$ & $7(3)$ \\
Vizinho & $25(6)$ & $7(3)$ \\
Colega de trabalho & $11(2,5)$ & $15(5)$ \\
Ex-colega de trabalho & $10(2)$ & $180(71)$ \\
Outro & $21(5)$ & $73(29)$ \\
\hline Reside na mesma cidade & & \\
Sim & $325(77)$ & $161(64)$ \\
Não & $98(23)$ & $21(8)$ \\
Conhecimento do status & & $71(28)$ \\
O amigo sabe & $270(64)$ & \\
O amigo não sabe & $17(4)$ &
\end{tabular}

Os resultados para tempo de amizade e contato semanal - face a face, por telefone e por e-mail - com o melhor amigo estão dispostos na Tabela 4 . A comparação de médias por sexo do participante conduzidas por meio do teste $t$ apontou diferença significativa apenas para contato semanal por telefone, com as participantes mulheres apresentando a maior média, destacando-se significativamente do grupo dos homens: $t(611)=2,51, \mathrm{p}<0,01$.

\section{TABELA 4}

Tempo de Amizade e de Contato Semanal com o Melhor Amigo, por Sexo do Participante

\begin{tabular}{lcccccc}
\hline & \multicolumn{2}{c}{ Média } & \multicolumn{2}{c}{ DP } & \multicolumn{2}{c}{$\mathrm{n}$} \\
\cline { 2 - 7 } Melhor amizade & $\mathrm{F}$ & $\mathrm{M}$ & $\mathrm{F}$ & $\mathrm{M}$ & $\mathrm{F}$ & 253 \\
\hline Tempo de amizade & 8,5 & 9,1 & 7,1 & 7,3 & 422 & 253 \\
\hline Contato semanal & & & & & & \\
Face a face & 2,5 & 2,5 & 2,4 & 2,1 & 396 & 244 \\
Por telefone & 2,4 & 2,0 & 2,3 & 2,1 & 385 & 229 \\
Por e-mail & 1,3 & 1,1 & 2,1 & 1,9 & 384 & 231 \\
\hline
\end{tabular}

Nota. $\mathrm{F}=$ feminino; $\mathrm{M}=$ masculino.

a Em anos. 
As médias para melhores amizades extras (total e por sexo da amizade) encontram-se na Tabela 5, dispostas por sexo do participante. As comparações de médias apontaram diferenças significativas para melhores amizades extras de mesmo sexo do participante, isto é, as mulheres indicaram mais melhores amizades extras com amigas, e os homens mais com amigos: $t(666)=9,82, \mathrm{p}<0,001$; e $t(666)=9,95, \mathrm{p}<0,001$, respectivamente.

TABELA 5

Sexo das Melhores Amizades Extras, por Sexo do Participante

\begin{tabular}{lcccccc}
\hline & \multicolumn{2}{c}{ Média } & \multicolumn{2}{c}{$\mathrm{DP}$} & \multicolumn{2}{c}{$\mathrm{n}$} \\
\cline { 2 - 7 } Melhores amizades extras & $\mathrm{F}$ & $\mathrm{M}$ & $\mathrm{F}$ & $\mathrm{M}$ & $\mathrm{F}$ & $\mathrm{M}$ \\
\hline Total & 2,2 & 2,0 & 1,5 & 1,6 & 423 & 253 \\
Amigas mulheres & 1,6 & 0,6 & 1,3 & 0,8 & 415 & 253 \\
Amigos homens & 0,6 & 1,4 & 0,8 & 1,3 & 415 & 253 \\
\hline
\end{tabular}

Nota. $F=$ feminino; $M=$ masculino.

\section{DISCUSSÃO}

Primeiramente são discutidos os resultados sobre as amizades próximas. Em seguida, são debatidos os resultados para as melhores amizades, seguidos da discussão dos achados sobre as melhores amizades extras.

Com relação às amizades próximas, os resultados mostraram uma predominância significativa de indicações de amizades de mesmo sexo. Como referido na introdução, amizades adultas são altamente homogêneas em vários aspectos, incluindo sexo, e os dados do presente estudo corroboram os achados empíricos com amostras estrangeiras (Bell, 1981; Blieszner \& Adams, 1992; Fehr, 1996; Parks \& Floyd, 1996). Com respeito aos demais aspectos investigados sobre amizades próximas, não foram encontradas diferenças de sexo do participante entre a média de amizades que residem na mesma cidade do participante e a média para amizades contatadas freqüentemente. De certo modo, estes resultados também vão ao encontro da mencionada homogeneidade nas amizades adultas, aspecto mais universal dessas amizades.

A indicação da melhor amizade também se destacou pela escolha de indivíduos de mesmo sexo, com as mulheres indicando mais mulheres como melhor amizade e os homens indicando mais homens para o posto mais elevado na rede de amizades. Esse resultado também é condizente com a busca por similaridades e a facilidade que este fator proporciona na formação das amizades (Fehr, 1996). Com respeito à origem da melhor amizade, note-se que os contextos mais indicados pelos participantes propiciam elevada freqüência de contato, conforme proposto por Fehr em seu modelo, dentro dos fatores ambientais, como co- légio, faculdade, trabalho, família e vizinhança. Todos estes ambientes são, portanto, férteis à formação da amizade e de seu desenvolvimento, proporcionando, inclusive, a passagem do status de amizade próxima ao de melhor amizade. Mais especificamente com respeito ao colégio como a origem mais mencionada, a literatura aponta que os anos escolares propiciam o desenvolvimento de amizades duradouras em função do surgimento de aspectos como lealdade e confiança, decorrentes do desenvolvimento social, afetivo e cognitivo dos indivíduos (Bukowski e cols., 1996). A única associação significativa encontrada entre sexo do participante e local de origem da amizade foi entre participantes homens e o ambiente da praia. Com relação a isso, entende-se que estes participantes muito provavelmente estão se referindo a melhores amizades que possivelmente se originaram ou de vizinhos de residência de férias de verão ${ }^{1}$, ou de atividades compartilhadas típicas do período de veraneio, como surfar e praticar esportes coletivos. Ambas as hipótesesexplicativas indicam, como referido na literatura, de um lado o papel importante da proximidade residencial como fator ambiental na formação das amizades (Fehr); de outro, o fortalecimento da variável similaridade (mediante interesses e atividades compartilhadas) na constituição da amizade em geral, mas especialmente entre homens (Wright, 1985).

O tipo de relacionamento atual entre o participante e sua melhor amizade evidencia aspectos importantes na discussão sobre amizades, como o envolvimento familiar. De fato, o argumento de Bell (1981) sobre as amizades entre familiares não figurarem como amizades genuínas é interessante ao evidenciar o papel da liberdade de escolha na seleção dos amigos; não é possível selecionar membros da família. Contudo, em 
se tratando de amizades adultas, como no presente estudo, entende-se que a experiência prévia com amizades proporcionada pelos anos escolares (da préescola à universidade) oferece fundamento consistente para que o indivíduo, mediante o exercício da liberdade de escolha - a princípio irrestrita na adultez com respeito à escolha de amigos, opte por investir em uma boa amizade tanto com um vizinho quanto com um irmão. Para tanto, serão considerados os mesmos fatores mencionados pela literatura sobre amizade (Bukowski e cols.), como companheirismo, ajuda instrumental, trocas afetivas, divertimento, confiança - aspectos encontrados também em membros da família.

A grande maioria dos participantes $(75 \%)$ relatou que a melhor amizade reside na mesma cidade, sem distinção por sexo do participante. Este resultado também vai ao encontro da importância da proximidade residencial como fator ambiental importante não apenas para a formação da amizade, mas igualmente para seu desenvolvimento, incluindo a alteração do status de amizade próxima (íntima) para melhor amizade.

A investigação sobre o conhecimento da melhor amizade sobre seu próprio status localizou uma tendência de participantes homens terem melhores amizades que não sabem de sua condição. Este resultado vai à mesma direção da proposta de Wright (1985), que argumenta que as mulheres valorizam mais o compartilhamento de experiências afetivas, na comparação com homens, fazendo com que estes últimos não compartilhem nas suas verbalizações o reconhecimento do amigo com sua melhor amizade.

O tempo de amizade não diferenciou significativamente entre homens e mulheres. Ainda assim, considerando-se a duração média observada entre oito e nove anos e o fato de a maioria dos participantes terem idade entre 18 e 30 anos $(90 \%)$, tanto a faculdade como a escola onde foi cursado o ensino médio apresentam-se como os prováveis contextos onde a melhor amizade do participante se formou, se desenvolveu e se mantém até a participação no presente estudo. Com respeito à freqüência de contato semanal com a melhor amizade, apenas o contato por telefone apontou diferença significativa para sexo do participante, com as mulheres destacando-se no uso do telefone. Este resultado se aproxima do compartilhamento de experiências afetivas nas conversas de amigas, um dos aspectos que a literatura menciona na distinção entre amizades femininas e masculinas (Wright, 1985). Note-se também que, no presente estudo, o uso do e-mail não se destacou como meio de contato fre- qüente entre melhores amigos. Contudo, estudos futuros podem averiguar mais detalhadamente sobre o tipo de contato e freqüência mediante o uso da Internet entre melhores amizades.

Finalmente, os resultados para sexo das melhores amizades extras foram semelhantes aos obtidos para sexo das amizades próximas, reafirmando a escolha por amizade de mesmo sexo como fator importante na formação e desenvolvimento destes relacionamentos. Contudo, o que se destaca no presente trabalho é a indicação da ausência de exclusividade na escolha da melhor amizade. Na verdade, há estudos que relatam encontrar muitos participantes sem uma melhor amizade (Monsour, 1992), o que suscita o questionamento de se a questão está na percepção do indivíduo do que seja uma melhor amizade ou se esse tipo de amizade é escasso em adultos. Da mesma forma, no presente trabalho pode-se questionar se o relato de melhores amizades extras é indicativo de uma reduzida seletividade na determinação do que seja uma melhor amizade, ou se se trata de melhores amizades que desempenham funções diferentes para o participante - por exemplo, com um melhor amigo se destacando por sua lealdade, e outro melhor amigo por sua confiança. Investigações futuras podem analisar mais detalhadamente estas questões, bem como outros aspectos não cobertos no presente estudo.

\section{REFERÊNCIAS}

Antoniazzi, A. S., Hutz, C. S., Lisboa, C. S. M., Xavier, C. A., Eickhoff, F., \& Bredemeier, J. (2001). O desenvolvimento do conceito de amigo e de inimigo em crianças e pré-adolescentes. Psico-USF, 6(2), 1-10

Argyle, M. (2001). The psychology of happiness ( $2^{\mathrm{a}}$ ed.). New York: Taylor \& Francis.

Bell, R. (1981). Meanings of friendship. Em R. Bell, Worlds of friendship (pp. 9-30). Beverly Hills: Sage.

Berscheid, E., \& Regan, P. (2005). The psychology of interpersonal relationships. Upper Saddle River: Pearson.

Blieszner, R., \& Adams, R. G. (1992). Adult friendship. London: Sage.

Bukowski, W. M., Newcomb, A. F., \& Hartup, W. W. (1996). Friendship and its significance in childhood and adolescence: Introduction and comment. Em W. M. Bukowski, A. F. Newcomb, \& W. W. Hartup (Orgs.), The company they keep: Friendship in childhood and adolescence (pp. 1-15). Cambridge: Cambridge University Press.

Daudt, P. (1997). Interação social: O papel da amizade no desenvolvimento infantil. Aletheia, 5, 80-90.

Erbolato, R. M. P. L. (2001). Contatos sociais: Relações de amizade em três momentos da vida adulta. Tese de doutorado nãopublicada, Pontifícia Universidade Católica de Campinas. 
Everitt, B. (1977). The analysis of contingency tables. London: Chapman and Hall.

Fehr, B. (1996). Friendship processes. London: Sage.

Kipper, A. (2003). Sobre a amizade: Relações de trabalho e bemestar subjetivo. Dissertação de mestrado não-publicada, Universidade Federal do Rio Grande do Sul, Porto Alegre.

Lisboa, C., \& Koller, S. H. (2003). Amizade e vitimização: Fatores de risco e proteção no contexto do grupo de iguais. PsicoPUCRS, 34(1), 71-94.

Monsour, M. (1992). Meanings of intimacy in cross- and samesex friendships. Journal of Social and Personal Relationships, 9, 277-295.

Parks, M. R., \& Floyd, K. (1996). Meanings for closeness and intimacy in friendship. Journal of Social and Personal Relationships, 13(1), 85-107.

Piotto, D. C., \& Rubiano, M. R. B. (1999). Amizade entre crianças pequenas: Análise da interação de pares preferenciais na creche. Psico-PUCRS, 30(1), 109-129.

Rezende, C. (2002). Os significados da amizade: Duas visões de pessoa e sociedade. Rio de Janeiro: FGV.

Rohde, L. A., Ferreira, M. H. M., Zomer, A., Forster, L., \& Zimmermann, H. (1998). The impact of living on the streets on la- tency children's friendships. Revista de Saúde Pública, 32(3), 273-280.

Souza, L. K., \& Hutz, C. S. (no prelo). A qualidade da amizade: Adaptação e validação dos Questionários McGill. Aletheia (Canoas).

Souza, L. K., Gauer, G., \& Hutz, C. S. (2004). Publicações em psicologia do desenvolvimento em dois periódicos brasileiros na década de 1990. Psico-USF, 9(1), 49-57.

Tortella, J. C. B. (2007). Um estudo sobre os sentimentos e os segredos de amizades infantis. Em L. R. P. Tognetta (Org.), Virtudes e educação: O desafio da modernindade (pp. 95-119). Campinas: Mercado de Letras.

Veenhoven, R. (1994). Correlates of happiness: 7838 findings from 603 studies in 69 countries 1911-1994. Rotterdam: Erasmus University.

Wright, P. (1985). The Acquaintance Description Form. Em S. Duck \& D. Perlman (Orgs.), Understanding personal relationships: An interdisciplinary approach (pp. 39-62). London: Sage.

Recebido: 11/06/2007

Última revisão: 05/12/2007 Aceite final: 18/12/2007

\footnotetext{
Notas:

${ }^{1}$ Este trabalho apresenta dados inéditos originados da tese de doutorado do primeiro autor, sob orientação do segundo, defendida no Programa de Pós-Graduação em Psicologia da Universidade Federal do Rio Grande do Sul. Nossos agradecimentos a C. Giacomoni, C. Ziviani, J. Sarriera, D. Bandeira e M. Mendelson. Apoio: CNPq/CAPES.
}

${ }^{2}$ Porto Alegre, cidade onde foi coletada a amostra para o presente estudo, situa-se a aproximadamente $110 \mathrm{~km}$ do litoral gaúcho.

\section{Sobre os autores:}

Luciana Karine de Souza: Mestrado e Doutorado pela Universidade Federal do Rio Grande do Sul. Professora Adjunta da Universidade Federal de Minas Gerais.

Claudio Simon Hutz: Mestrado e Doutorado pela University of Iowa. Professor Titular da Universidade Federal do Rio Grande do Sul.

Endereço para correspondência: Universidade Federal do Rio Grande do Sul - Instituto de Psicologia, Laboratório de Mensuração Rua Ramiro Barcelos, 2600 - sala 101 - 90035-003 - Porto Alegre/RS - Endereço eletrônico: lucianak@fafich.ufmg.br. 